\title{
Effect of removal of epididymal secretions on fertilization in vitro of mouse eggs
}

\author{
Lynn R. Fraser and Linda M. Drury* \\ Clinical Research Centre, Watford Road, Harrow, Middlesex HAI $3 U J$, and * Department of \\ Obstetrics and Gynaecology, University College Hospital, London, WCIE 6DH, U.K.
}

\begin{abstract}
Summary. The removal by centrifugation of epididymal contents from mouse spermatozoa had no deleterious effect on fertilization in vitro, and, depending on the genotype of the gametes, was frequently associated with increased levels of fertility. Washing of the spermatozoa significantly improved the fertilization rate of $F_{1}$ eggs with TO spermatozoa and of BALB/c eggs with BALB/c spermatozoa, but had no significant effect on $F_{1}$ spermatozoa with $F_{1}$ eggs.
\end{abstract}

\section{Introduction}

The role, if any, of epididymal secretions in the induction of capacitation of mouse spermatozoa in vitro has yet to be defined. Iwamatsu \& Chang (1971) reported that epididymal secretions appeared to inhibit sperm penetration in vitro, but the level of fertilization obtained in the control group, i.e. lacking epididymal secretions, was so low $(<10 \%)$ that interpretation of the results is difficult. Oliphant \& Brackett (1973) found that addition of epididymal extracts to capacitated mouse spermatozoa markedly reduced the fertilization rate, suggesting a decapacitating effect. In contrast, Gwatkin, Andersen \& Williams (1974) have suggested that epididymal secretions can induce capacitation and that, in the absence of cumulus cells, they are necessary for capacitation. In the light of these conflicting reports the following experiments were carried out to compare the fertilization rates obtained with unwashed and washed sperm suspensions. The effect of gamete genotype on the response to washing was also examined by using several strain combinations.

\section{Materials and Methods}

Unfertilized eggs were recovered $13 \mathrm{hr}$ after administration of HCG from 8-16-week-old (C57BL/ $10 \times \mathrm{CBA}) \mathrm{F}_{1}$ or BALB/c females induced to superovulate by i.p. injections of 5 i.u. PMSG (Gestyl: Organon) and 5 i.u. HCG (Pregnyl: Organon) $48 \mathrm{hr}$ later. The media and methods used for preparation of dishes were exactly those described by Fraser \& Drury (1975). Deionized water from Flow Laboratories was used to prepare the media.

Depending on the experiment, spermatozoa were recovered from 8-16-week-old outbred TO, $(\mathrm{C} 57 \mathrm{BL} / 10 \times \mathrm{CBA}) \mathrm{F}_{1}$ or BALB/c males. One vas deferens and one epididymis from each of two males were placed in an embryological watchglass containing $1 \mathrm{ml}$ fertilization medium and $2 \mathrm{ml}$ paraffin oil (Boots) which had been equilibrated overnight with $5 \% \mathrm{CO}_{2}+5 \% \mathrm{O}_{2}+90 \% \mathrm{~N}_{2}$. Spermatozoa were gently extruded from the ducts by squeezing with watchmaker's forceps and allowed to disperse for $20 \mathrm{~min}$. Two dishes of spermatozoa were thus obtained from 2 males, and to completely randomize spermatozoa the contents of the dishes were pooled. Half of the sperm suspension $(1 \mathrm{ml})$ was transferred to a conical centrifuge tube and centrifuged at $650 \mathrm{~g}$ (MSE Minor centrifuge) for $4 \mathrm{~min}$. After removal of the supernatant (Supernatant 1), the pellet (Pellet 1) was resuspended in $1 \mathrm{ml}$ fertilization medium and the procedure repeated. The resuspended pellet material therefore contained concentrated washed spermatozoa.

In experiments designed to examine the effect of re-addition of epididymal secretions to washed spermatozoa, Supernatant 1 was placed in a test tube, gassed with $5 \% \mathrm{CO}_{2}+5 \% \mathrm{O}_{2}+90 \% \mathrm{~N}_{2}$ to 
maintain $\mathrm{pH}$, and the tube was stoppered. The resuspended Pellet 1 was divided into two aliquots of $0.5 \mathrm{ml}$ and centrifuged a second time. The resulting pellets were resuspended, one in $0.5 \mathrm{ml}$ fertilization medium and the other in $0.5 \mathrm{ml}$ Supernatant 1 . All concentrated suspensions were then diluted $1: 9$ and $0.5 \mathrm{ml}$ of this suspension was pipetted into a dish containing paraffin oil to give a final sperm concentration of approximately $10-30 \times 10^{5} / \mathrm{ml}$. Eggs were released from the ampullae of the oviducts directly into the sperm suspensions.

In all experiments gametes were incubated for 5-6 hr. Eggs were then washed twice in culture medium and transferred to $50 \mu \mathrm{l}$ droplets of culture medium under paraffin oil in plastic culture dishes (Falcon Plastics). Eggs were examined $24 \mathrm{hr}$ after mixing with spermatozoa for cleavage to the 2-cell stage and at subsequent 24 -hr intervals for further development. The number of blastocysts obtained after 5 days total culture was recorded and the culture rate, defined as the number of blastocysts obtained from 2-cell embryos, was determined. Since BALB/c eggs do not culture well beyond the 2-cell stage, these results have not been included.

For statistical analysis of the results, Cochran's test for combination of $2 \times 2$ contingency tables was used (Snedecor \& Cochran, 1967).

\section{Results}

The sperm concentrations used in the experiments have been included with the results shown in Tables 1 and 2; these concentrations are within the range shown to give high rates of fertilization in this system (Fraser \& Drury, 1975). The fertilization of $F_{1}$ eggs with TO spermatozoa was significantly

Table 1. Fertilization in vitro (no. of 2-cell embryos/total no. of eggs) of mouse eggs with unwashed and washed spermatozoa

\begin{tabular}{|c|c|c|c|}
\hline Exp. & $\begin{array}{l}\text { Sperm conc. } \\
\left(\times 10^{5} / \mathrm{ml}\right)\end{array}$ & Unwashed sperm. (\%) & Washed sperm. (\%) \\
\hline \multicolumn{4}{|c|}{ (a) $F_{1}$ eggs + TO spermatozoa } \\
\hline 1 & $32 \cdot 3$ & $58 / 90 \quad(65)$ & $65 / 75 \quad(87)$ \\
\hline 2 & $15 \cdot 5$ & $48 / 61 \quad(79)$ & $70 / 76 \quad(92)$ \\
\hline 3 & $15 \cdot 7$ & $57 / 69 \quad(83)$ & $67 / 72 \quad(93)$ \\
\hline 4 & $18 \cdot 8$ & $80 / 98 \quad(82)$ & $77 / 80 \quad(96)$ \\
\hline 5 & $18 \cdot 7$ & $50 / 66 \quad(76)$ & $44 / 51 \quad(86)$ \\
\hline 6 & $31 \cdot 6$ & $73 / 86 \quad(85)$ & $63 / 75 \quad(84)$ \\
\hline 7 & $26 \cdot 5$ & $28 / 43 \quad(65)$ & $36 / 49$ (73) \\
\hline 8 & $23 \cdot 4$ & $41 / 54 \quad(76)$ & $33 / 42$ (79) \\
\hline 9 & $20 \cdot 8$ & $40 / 42$ (95) & $39 / 43 \quad(91)$ \\
\hline Total & & $475 / 609(78)$ & $494 / 563(88)$ \\
\hline Culture rate & & $285 / 338(84)$ & $331 / 422(78)$ \\
\hline \multicolumn{4}{|c|}{ (b) $F_{1}$ eggs $+F_{1}$ spermatozoa } \\
\hline 1 & $18 \cdot 4$ & $39 / 49 \quad(80)$ & $33 / 47 \quad(70)$ \\
\hline 2 & $21 \cdot 0$ & $32 / 45 \quad(71)$ & $49 / 61(80)$ \\
\hline 3 & $20 \cdot 7$ & $28 / 40$ & $25 / 50 \quad(50)$ \\
\hline 4 & $11 \cdot 6$ & $36 / 53 \quad(68)$ & $47 / 62 \quad(76)$ \\
\hline 5 & $24 \cdot 4$ & $71 / 80(89)$ & $43 / 59 \quad(73)$ \\
\hline 6 & $21 \cdot 2$ & $43 / 47 \quad(92)$ & $44 / 48 \quad(92)$ \\
\hline Total & & $249 / 314(79)$ & $241 / 327(74)$ \\
\hline Culture rate & & $220 / 249(88)$ & $217 / 241(90)$ \\
\hline \multicolumn{4}{|c|}{ (c) $B A L B / c$ eggs $+B A L B / c$ spermatozoa } \\
\hline 1 & $16 \cdot 1$ & $14 / 20(70)$ & $16 / 20 \quad(80)$ \\
\hline 2 & $17 \cdot 5$ & $1 / 12$ & $9 / 17 \quad(53)$ \\
\hline 3 & $10 \cdot 0$ & $1 / 18 \quad$ (5) & $6 / 14(43)$ \\
\hline 4 & $19 \cdot 0$ & $6 / 14 \quad(43)$ & $20 / 23 \quad(83)$ \\
\hline Total & & $22 / 64 \quad(34)$ & $51 / 74 \quad(69)$ \\
\hline
\end{tabular}

* No. of blastocysts/no. of 2-cell embryos. 
increased $(P<0.001)$ when washed spermatozoa were used (Table 1), except when the rate obtained with unwashed spermatozoa was already high (e.g. Exp. 9). With BALB/c spermatozoa and eggs, the fertilization rate was again significantly higher $(P<0.001)$ after washing but there was no significant difference $(P>0.05)$ between washed and unwashed spermatozoa when $\mathrm{F}_{1}$ spermatozoa and eggs were used (Table 1).

Experiments comparing the fertilizing ability of TO spermatozoa which were (A) unwashed, (B) washed and $(C)$ washed and resuspended in epididymal secretions (Table 2) showed that there was a significant increase in fertilization rate when spermatozoa were washed $(P<0.01)$, but a significant decrease when washed spermatozoa were resuspended in Supernatant $1(P<0.001)$.

Table 2. Fertilization in vitro (no. of 2-cell embryos/total no. of eggs) of $F_{1}$ mouse eggs with TO spermatozoa which were unwashed (Group A), washed (Group B), and washed and re-suspended in epididymal secretions (Group C)

\begin{tabular}{lcccc}
\hline Exp. & $\begin{array}{c}\text { Sperm conc. } \\
\left(\times 10^{5} / \mathrm{ml}\right)\end{array}$ & Group A (\%) & Group B (\%) & Group C (\%) \\
\hline 1 & $18 \cdot 5$ & $40 / 53(76)$ & $46 / 54(85)$ & $16 / 45(36)$ \\
2 & $23 \cdot 6$ & $42 / 49(86)$ & $35 / 38(92)$ & $33 / 62(53)$ \\
3 & $22 \cdot 5$ & $27 / 27(100)$ & $35 / 37(95)$ & $16 / 29(55)$ \\
4 & $16 \cdot 8$ & $15 / 27(56)$ & $34 / 37(92)$ & $10 / 41(24)$ \\
5 & $16 \cdot 1$ & $43 / 48(90)$ & $34 / 37(92)$ & $31 / 33(91)$ \\
Total & & $167 / 204(82)$ & $184 / 203(91)$ & $106 / 210(51)$ \\
Culture rate* & & $100 / 124(81)$ & $111 / 150(74)$ & $62 / 75(83)$ \\
\hline
\end{tabular}

* No. of blastocysts/no. of 2-cell embryos.

In all experiments the culture rates were similar, irrespective of the presence or absence of epididymal secretions at the time of fertilization (Tables 1 and 2), ranging from 74-90\%. Within each series of experiments the range was even less. In a few experiments infection prevented completion of culture and affected embryos were not used in determining the culture rate. Earlier studies with this in-vitro system have shown that most embryos are diploid and that they can develop into viable young when transferred to pseudopregnant recipients (Fraser \& Drury, 1975).

\section{Discussion}

The present results indicate that the removal of epididymal secretions has no deleterious effect on fertilization with the strain combinations examined and may even result in an increased level of fertility. Although the spermatozoa were allowed to disperse for 20 min to achieve maximum motility (Pavlok \& McLaren, 1972), it seems unlikely that epididymal fluids would have an initial positive effect and then, rapidly, a negative one. The effect obtained after washing spermatozoa is partly dependent on the genotype of the spermatozoa since washing generally increased the fertility of those from $T O$ mice, yet had no significant effect on those from $F_{1}$ mice when both were incubated with $F_{1}$ eggs. These differences cannot simply be due to strain specificity, since washing also significantly improved the fetility of BALB/c spermatozoa when tested with BALB/c eggs, although there was a gradation from no effect $\left(F_{1} \times F_{1}\right)$ to a slight improvement $\left(F_{1} \times T O\right)$, to a great improvement $(\mathrm{BALB} / \mathrm{c} \times \mathrm{BALB} / \mathrm{c})$ with removal of epididymal fiuid.

The beneficial effect of washing on TO spermatozoa could indicate the presence of a decapacitation factor in epididymal fluid as suggested by Oliphant \& Brackett (1973). Washing would remove the factor and resuspension of washed spermatozoa in Supernatant 1, containing the epididymal fluid, would reintroduce the factor and result in decreased fertility. This is consistent with the generally reduced fertility of spermatozoa treated in this way (Table 2). The fact that unwashed spermatozoa usually show quite high fetility suggests that much of such a decapacitation factor diffuses away quickly or is inactivated when spermatozoa are dispersed in the fertilization medium. Another 
possible explanation is that washing removes substances released by damaged spermatozoa which might interfere with fertilization.

Unwashed TO spermatozoa give high levels of fertilization and, furthermore, have a relatively rapid penetration rate (time required for sperm: egg fusion) of $1 \frac{1}{2} \mathrm{hr}$ with $\mathrm{F}_{1}$ eggs (Fraser \& Drury, 1976). $F_{1}$ spermatozoa, however, do not respond to washing and yet the penetration rate of unwashed spermatozoa is considerably slower, requiring $2 \frac{1}{2}$ hr for completion (Fraser \& Drury, 1976). These results suggest that we are not dealing simply with a decapacitation factor which must be removed before spermatozoa can fertilize.

Although Gwatkin et al. (1974) have suggested that epididymal fluid can induce capacitation, the present experiments do not support this hypothesis. Furthermore, there is no detectable reduction in fertilization rate when results with cumulus-devoid eggs and washed TO spermatozoa are compared with those from cumulus-intact eggs and either washed or unwashed spermatozoa (L.R. Fraser, unpublished resuits). However, the medium used by Gwatkin et al. (1974) contained $3 \mathrm{mg} \mathrm{BSA} / \mathrm{ml}$ while the medium used in the present experiments contained $32 \mathrm{mg} \mathrm{BSA} / \mathrm{ml}$, and Miyamoto \& Chang (1973) have suggested that serum albumin is the most important component of media used for invitro work. These conflicting results may just reflect variations among strains of mice (Braden, 1958), and the results obtained with the three strains examined in the present study demonstrate that wide variability does exist.

\section{References}

BRADEN, A. (1958) Variation between strains of mice in phenomena associated with sperm penetration and fertilization. J. Genet. 56, 37-47.

Fraser, L. \& DRURY, L. (1975) The relationship between sperm concentration and fertilization in vitro of mouse eggs. Biol. Reprod. 13, 513-518.

Fraser, L. \& DruRY, L. (1976) Mouse sperm genotype and the rate of egg penetration in vitro. J. exp. Zool. (in press).

Gwatkin, R., Andersen, O. \& Williams, D. (1974) Capacitation of mouse spermatozoa in vitro: involvement of epididymal secretions and cumulus oophorus. J. Reprod. Fert. 41, 253-256.

IwamatsU, T. \& ChaNG, M. (1971) Factors involved in the fertilization of mouse eggs in vitro. $J$. Reprod. Fert. 26, 197-208.
Miyamoto, H. \& Chang, M. (1973) The importance of serum albumin and metabolic intermediates for capacitation of spermatozoa and fertilization of mouse eggs in vitro. J. Reprod. Fert. 32, 193205.

Oliphant, G. \& Brackett, B. (1973) Capacitation of mouse spermatozoa in media with elevated ionic strength and reversible decapacitation with epididymal extracts. Fert. Steril. 24, 948-955.

PAVlok, A. \& McLaren, A. (1972) Role of cumulus cells and the zona pellucida in fertilization of mouse eggs in vitro. J. Reprod. Fert. 29, 91-97.

SNEDECOR, G. \& COCHRAN, W. (1967) Statistical Methods, 6th edn. Iowa State University Press, Ames, Iowa. 